simple correlation between grades of reticulin or collagen and any of the basic data. These results are considered in greater detail in Part II.

Fibrous dust nodules are often seen in dusty lungs, and were present in 15 cases. They appear to occur mainly in those lungs which contain most dust but the lung of Case 1 with only $1.4 \mathrm{~g}$. of total dust contained a moderate number of nodules. Cases 11 and 15 also contained a few nodules despite relatively low dust content and this suggests that the nodules are probably not produced by dust alone. Infection is considered to be a likely additional factor, and, since nodules are more prevalent in the apex of the lung, tuberculous infection was suspected (Gough, 1947).

None of the cases showed macro or microscopic changes suggesting silicosis.

\section{Analysis of Results \\ 3.0 Possible Hypotheses}

In this series of coalworkers' lungs, tissue reaction to the dust was only slight and no case showed a silicotic type of reaction. There is abundant evidence that coal and silicates are relatively non-fibrogenic (Worth and Schiller, 1954). This suggests as a simple hypothesis that radiological changes in the chest are produced by inert dust and so depend only on the amounts of some or all the different dust components in the lung. If the tissue reaction to the dusts, although small, does influence the radiological picture and if the reaction is a very slow one, lasting many years, the period of retention will also be important; on the other hand, if tissue round a particular dust focus is formed over, say, one or two years only, and no more is formed after that, then the radiological changes would again depend on total amounts of dust and not directly upon periods of retention. It is possible, too, that one kind of dust is inert and another active. Finally nearly half the cases had emphysema and/or nodules and these might affect the radiographs. The data provide an opportunity of assessing these hypotheses quantitatively. The details of this are in Part II.

\subsection{Main Conclusions}

There is a better correlation of radiological changes and lung dust content when all independent readings for each radiograph are used instead of the "agreed" value.

Contributions to the radiological changes from the coal and silicate minerals have to be allowed for separately.

The radiological scale was transformed into a more nearly linear one in which equal intervals correspond to equal amounts of dust of a given composition. One gram of silicates was found to contribute about as much to the radiological changes as $9 \mathrm{~g}$. coal and an explanation of this difference based on unequal absorption of $x$ rays is suggested. The possible contribution of the quartz content to the radiological changes could not be reliably assessed as it was too highly correlated with the silicate content. The correlation between radiological change and dust content is not improved by allowing for the period of dust retention in the lung and the amount of tissue reaction to this dust. Thus it appears that in this type of simple pneumoconiosis the radiological changes are due to the amounts of coal and silicates in the lung and not to tissue reaction.

Data on the concentration and size distribution of the airborne dust to which the 45 men were exposed during their work underground are not known. Hence we cannot estimate the proportion of dust deposited in the lungs which is permanently retained. Our results show wide variation of rates of dust retention but provide no evidence on how these rates depend on differences in average dust concentration, different abilities to eliminate dust from the lungs, or other variables.

Estimates are given of the rate dust is permanently retained in the lungs and how this is related to the radiological progression of simple pneumoconiosis.

\title{
Part II: DETAILED ANALYSIS OF THE DATA \\ BY
}

\section{RIVERS and M. E. WISE}

\subsection{Comparison of Weight of Dust in Lung with Radiological Category}

Of all the variables given in Table 1, the total weight of dust seemed to be most closely associated with radiological change. The first detailed analysis indicated wide variation among individuals com- bined with astonishing simplicity in the average behaviour. This is seen as follows: The bottom of category 0 , although not defined by a standard film, corresponds to a lung quite free from dust and can reasonably be called zero on a scale $\mathrm{x}$ of continuous radiological change. The top of category 0 , that is 
the $0-1$ boundary, is called $x=1$; similarly $x=2$ is taken to correspond to the 1-2 boundary and $x=3$ to the 2-3 boundary. Next we assume that the numbers of subjects in category $0,1,2$, and 3 were really 17 , nine, 10 , and nine respectively as actually observed, even though it is improbable that all films were correctly classified. This is reasonable in view of other studies of observer error (Wise, in the press) which suggests that the number of 0 s classified as $1 \mathrm{~s}$ is nearly compensated for by the number of $1 \mathrm{~s}$ classified as $0 \mathrm{~s}$; similarly for $1 \mathrm{~s}$ read as $2 \mathrm{~s}$ and so on.

The 45 cases are now arranged in increasing order of total dust content. - If this is the only variable controlling radiological change the $0-1$ boundary should correspond to a total dust content about mid-way between the 17th and 18th cases, the 1-2 boundary between the 26th and 27th $(17+9=26)$ and the 2-3 boundary between the 36th and 37th cases $(17+9+10=36)$. On this basis the three radiological category boundaries, $x=1,2$, and 3 , correspond to 6,12 , and $18 \mathrm{~g}$. of dust in the lungs. Thus a plot of dust content against $\mathrm{x}$ values is linear and passes through the origin. Remembering that the scale of $x$ values was defined arbitrarily in terms of three standard films (Fletcher and Oldham, 1951), it suggests that these were well chosen.

A more refined analysis seems to confirm this finding. Two improvements can be made at once.
The first is to use all four readings of each film and not just the agreed reading. Of the 17 agreed to be category 0,11 had been read as 0 all four times. There was less dust in these lungs than in any of the remaining six, and of the latter the ones read as $0,0,0$, and 1 had, on the average, less dust than those read as $0,0,1$, and 1 . The films read as $0,0,0$, and 1 are scored as $x=\frac{3}{4} ; 0,0,1$, and 1 as $\mathrm{x}=1 ; 1,1,1$, and 1 as $\mathrm{x}=1 \frac{1}{2}$ and so on; obviously $\frac{1}{2}$ has to be added to each average of four categories. Each film is thus classified in terms of quarter categories instead of whole ones.* This crude average yields a surprising amount of information. Fig. 5, with averages replacing discrete categories, shows a better correlation than Fig. 4, at least at the lower end.

\subsection{Distribution of Continuous Radiological Changes and Total Weights of Dust}

This concept of averaging regards each reading of a film as an attempt to measure a continuous variable, namely the amount of simple pneumoconiosis. The second improvement is to regard the true radiological changes in the population of 45 as being well described by a continuous distribution. The

*It was more convenient to express the average category values as $4 \mathrm{x}$ (column 8 . Table 1 ).

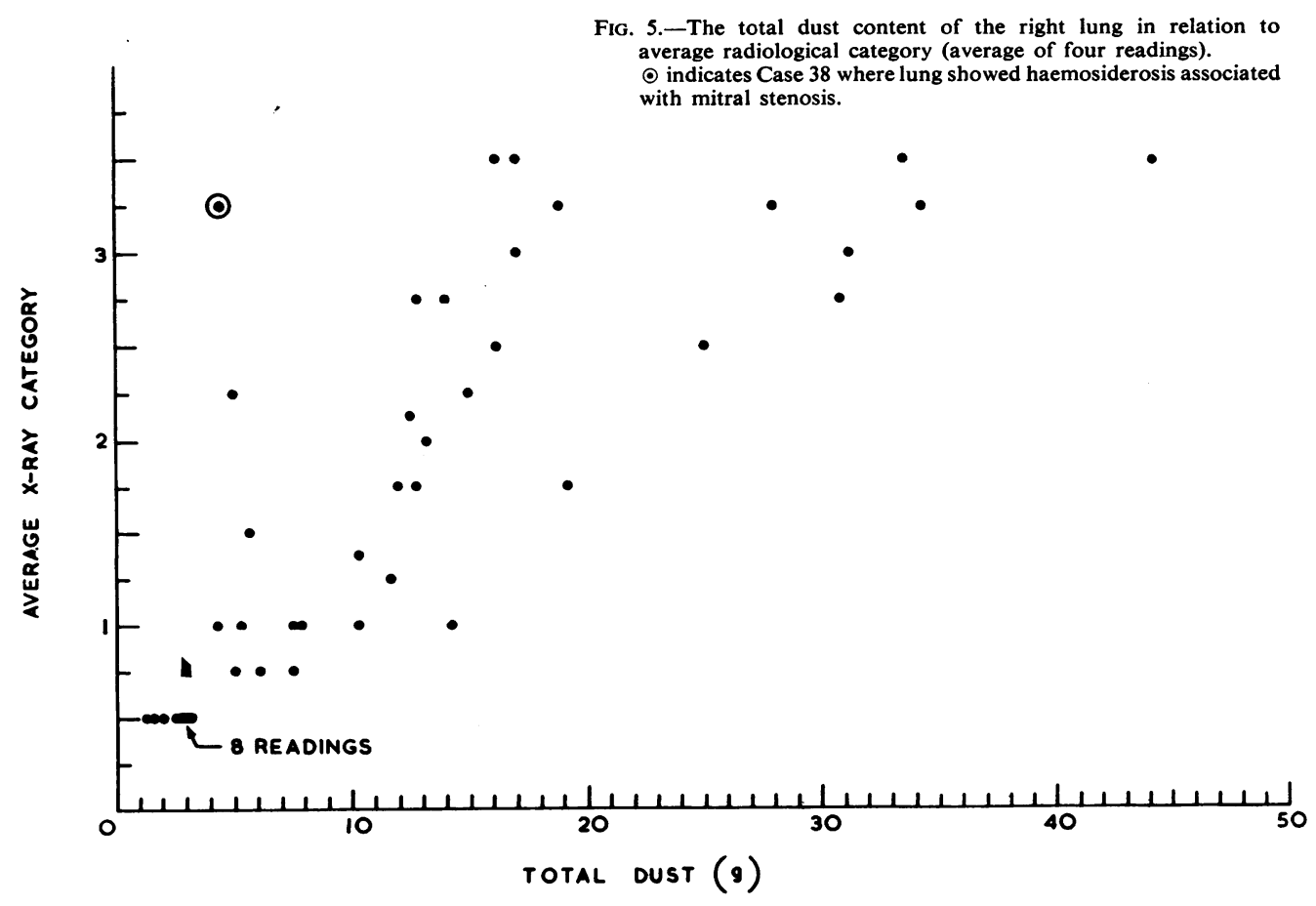




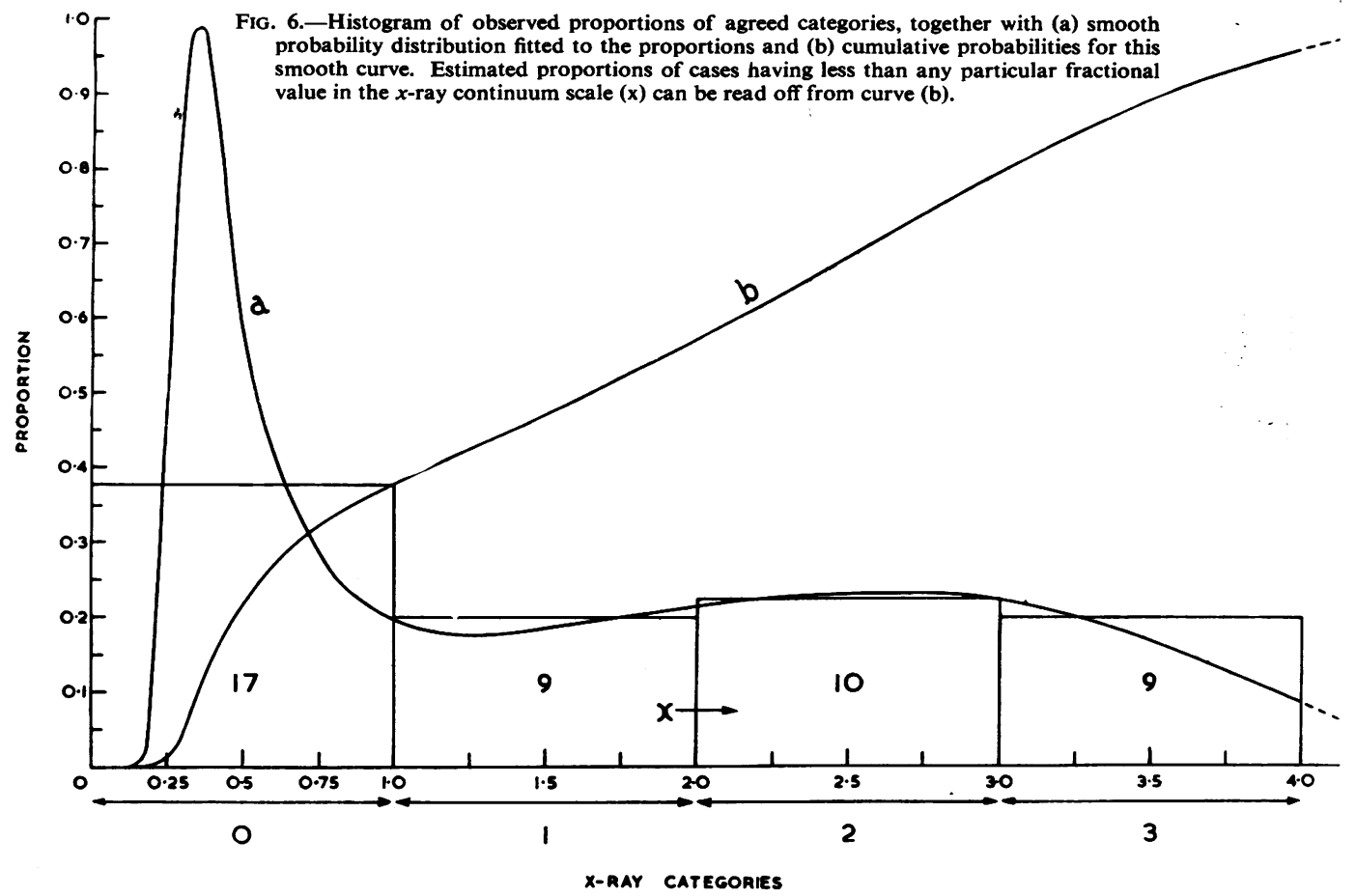

histogram of frequencies in Fig. 6, showing the 17 , nine, 10, and nine category $0 \mathrm{~s}, 1 \mathrm{~s}, 2 \mathrm{~s}$, and $3 \mathrm{~s}$ respectively, is replaced by the continuous distribution (a) and the corresponding cumulative proportions by (b), so that we assume, for example, that $47 \%$ of this population of 45 have radiological changes greater than 1.5 on this continuous scale. The mathematical calculations leading to these curves are not relevant to the main argument and are given in Appendix A; the type of distribution chosen was the same as that used to fit distributions of categories in populations of faceworkers in single pits. It was surprising that it fitted this very different population. Any other reasonable choice of smooth curve would have yielded distributions close to (a) and (b) except for values low in category 0 and values high in category 3 .

The 45 cases ranked in order of weight of dust can now be compared with fractional radiological values as well as with category boundaries: for example, the weight of dust halfway between the 18 th and the 19th, namely $6.8 \mathrm{~g}$., should correspond to the value for $40 \%(18 / 45=0.40)$, i.e., to the 40th percentile, obtained from curve (b) in Fig. 6. A smoothed curve was based on points obtained in this way all along the continuum except at its end and it is close to the line in Fig. 7. This seems to confirm the straight line through the origin.

\subsection{Factors Other than Total Dust Affecting Radiological Changes}

Fig. 7 shows that the scatter about this line is large. The vertical distances of plotted points from the line estimate over- and under-reading of average categories compared with values expected on the simple total dust hypothesis. The fact that the readings cannot be closer than the nearest quarter category is not taken into account but in many cases the distances are much greater than this. The other variables to which the scatter might be related are composition of the dust, duration of exposure to dust, age of the subject, and pathological changes, e.g., cases with emphysema were thought to be under-read and those with fibrous nodules over-read (Gough et al., 1949).

Only one of these factors has any obvious influence, but its effect proved so large as to invalidate the simple hypothesis that only total dust changes the radiological picture. This factor was the ratio of the coal to the mineral content of the dust. Fig. 8 is a plot of this ratio against the estimates of over- and under-reading. Clearly over-reading tends to go with a high mineral content, i.e. (low coal/mineral ratio), and under-reading with a low one. The points that are exceptions to this trend were not found to be peculiar in other respects such as age, years worked underground, or pathological changes. 


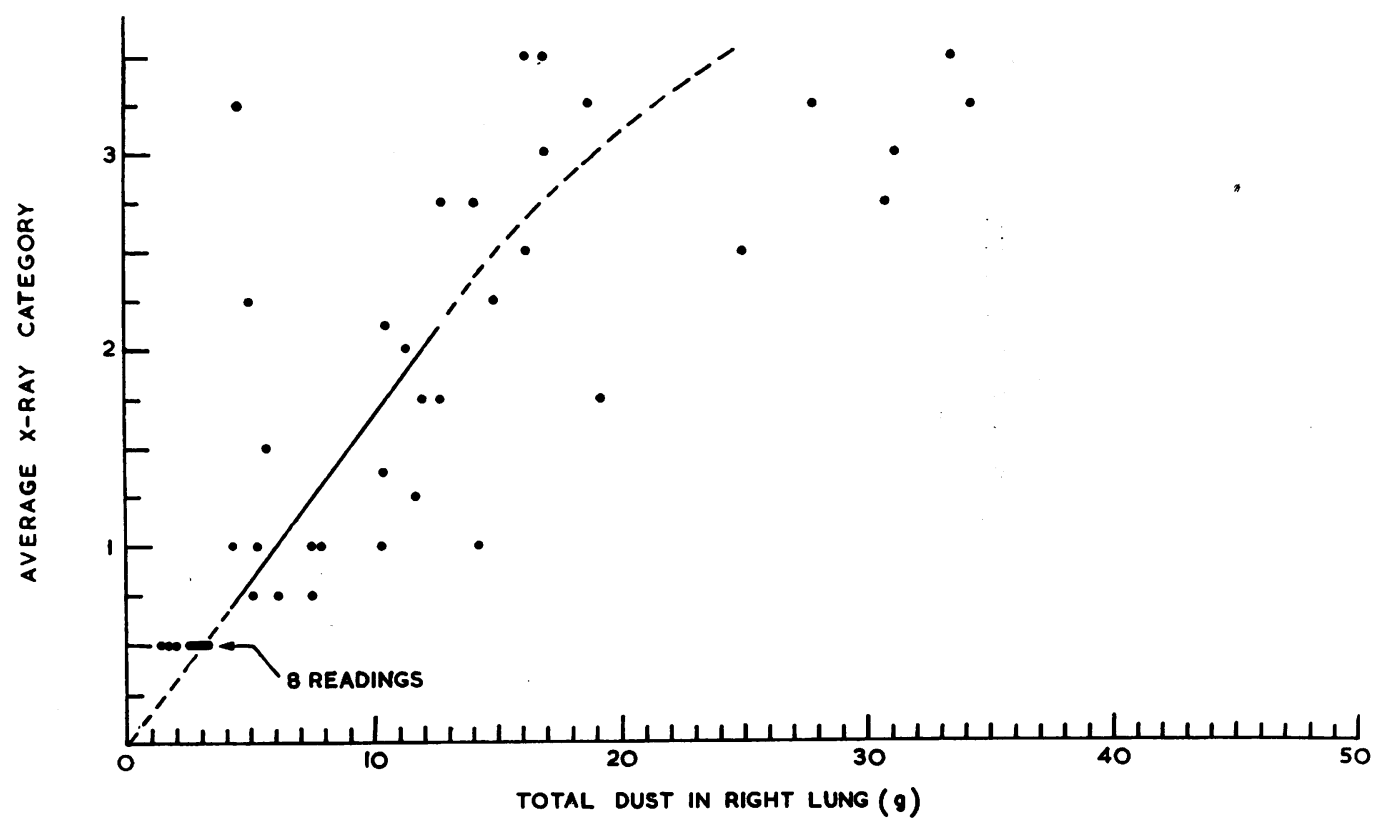

Fig. 7.-Fitted line to relationship of average radiological category to total dust content of right lung based on assumption that radiological changes are due only to total amount of dust in the lung.

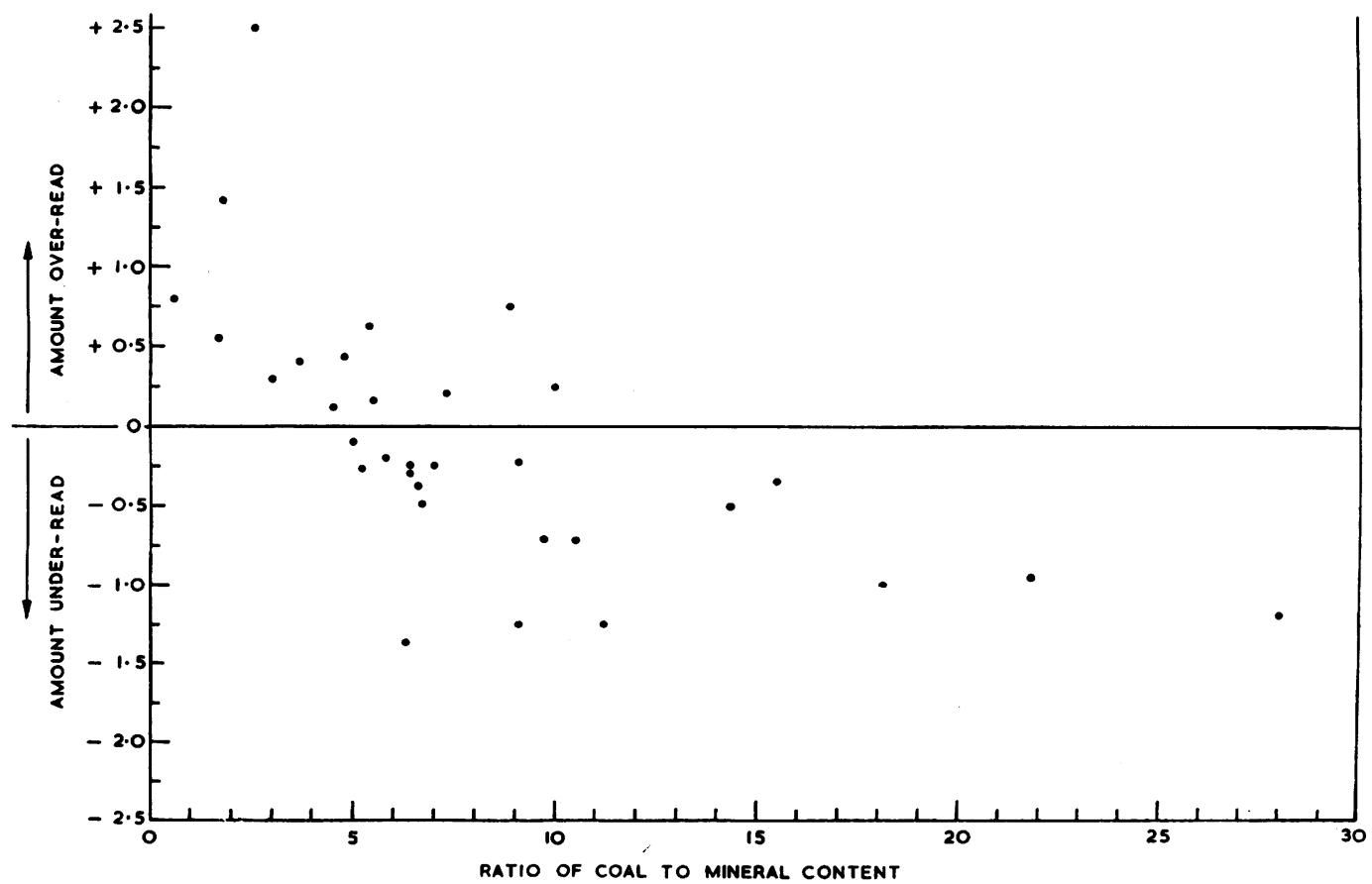

FIG. 8. - Over- and under-reading of average radiological category as estimated from Fig. 7 in relation to the ratio of coal to mineral content of the lungs. 
4.3 Components of Dust and Radiological Changes

The analysis was therefore repeated, treating coal, quartz, and siliceous minerals separately. The first step was to examine their relative contributions to radiological change. It was still assumed that these changes depended only on the weights of the component dusts and not on how and when they were retained. A linear relationship was fitted to the average category (the average of 4 scored as described), so that the predicted value, $X$, corresponding to an observed average $x$ value, is given by:-

$$
\mathbf{X}=\mathrm{b}_{\mathrm{o}}+\mathrm{b}_{\mathrm{C}} \mathrm{C}+\mathrm{b}_{\mathrm{Q}} \mathbf{Q}+\mathrm{b}_{\mathrm{S}} \mathbf{S}
$$

Here the amounts of dust are $\mathrm{C} g$. of carbon, $\mathbf{Q}$ g. of quartz and $\mathbf{S} \mathbf{g}$. of siliceous minerals and the $b_{C}, b_{Q}$, and $b_{S}$ are the corresponding contributions per gram to the radiological changes; $b_{0}$ is the amount of change when there is no coal or mineral dust. The estimated values are:-

$$
b_{\mathrm{O}}=0.264 ; \mathrm{b}_{\mathrm{C}}=0.057 ; \mathrm{b}_{\mathrm{Q}}=2.92 ; \mathrm{b}_{\mathrm{S}}=0.29 \text {. }
$$

They were obtained by least squares, leaving out the extreme cases; the four read as category 3 each time (since the upper end of category 3 is unknown) and the 11 cases read as category 0 (since the conclusion that the lower end of category 0 is really at zero might now no longer be valid).

The situation at the lower end is less clear than at the upper end. Since on the total dust hypothesis all these films were read "correctly" they can supply no new information on the effect of composition of the dust, but do later help to estimate the "distance across category 0". If some of these 11 cases contained so much mineral dust that on the new hypothesis their average categories should have been greater than 1, this would provide evidence against a large contribution to radiological change from mineral dust. In fact this is not so, but we shall see that other variables that could conceivably be important are large in some of these 11 cases, which then provide evidence against these variables influencing the radiological readings.

The standard errors of $b_{Q}$ and $b_{S}$ are large, but the errors in estimating these coefficients are negatively correlated, so that the estimate of the combined contribution from the quartz and silicate content of each lung in the series, namely $b_{Q} Q+b_{s} S$ is fairly reliable. In Fig. 9, observed and expected values are compared by plotting $x$ (observed) against $b_{o}+b_{C} C+b_{Q} Q+b_{s} S$ (the expected values of average category correspond to a $45^{\circ}$ straight line through the origin). It looks as if the relationship is no longer linear, for nearly all the points with expected values (of $X$, according to the amounts of the three components of dust) between 4 and 6 have observed average categories $x$ less than the expected ones, and hence lie above the $45^{\circ}$ line.
Fig. 9.-The plotted points have as abscissae the observed average radiological categories $(\mathrm{X})$ and as ordinates the corresponding expected ones (x), from equation 1 as described in Section 4.3, allowing for the three dust components separately. The abscissae are identical with the ordinates of Figs. 5 and 7. Comparison of Figs. 7 and 9 shows the better correlation of average category with dust content when composition is allowed for. The curve represents the adjusted radiological scale $\left(x^{\prime}\right)$ in which the relationship between amount of dust and radiological change is more nearly linear. The two broken curves are possible extrapolations.'

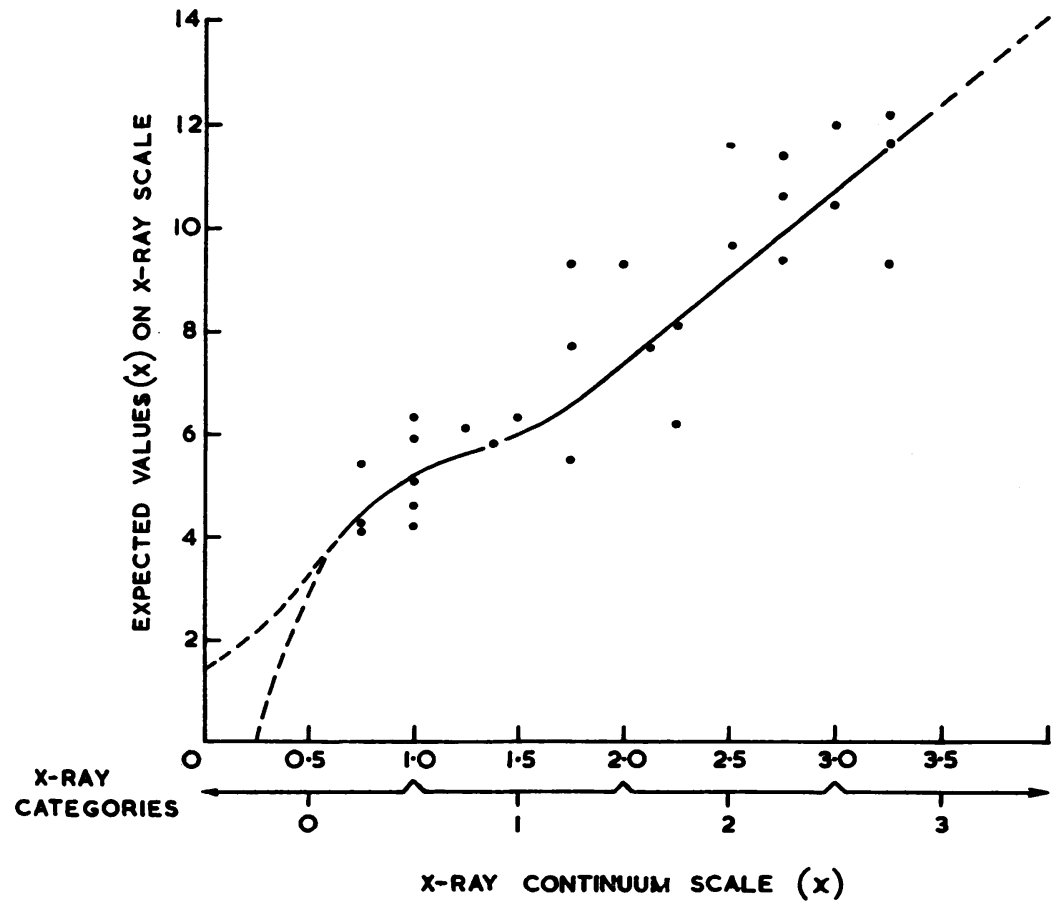


Elsewhere the points lie at random about the line.

In order to test whether the radiological scale is linear now that components of the dust are allowed for separately, and if not to replace it by one that is linear, we repeat the ranking process described in section 4.1. Now, however, the 45 cases are not ranked in terms of total dust but according to the function of their component dusts defined by equation (1). Percentiles on the radiological category scale, obtained from curve b in Fig. 6, are then compared with those obtained from the rankings of values given by this equation. The result is shown by the smooth curve in Fig. 9; the actual scorings for each quarter category are given in Table 6. (They are multiplied by 4 to give a convenient scale $x^{\prime}$.) The radiological change is measured on this new adjusted scale $x^{\prime}$ in place of the previous continuum $x$ scale (details in Appendix B); it is more nearly linear in terms of amounts of the three dust components. The main difference between the continuum and adjusted scales is at the lower end; here the smooth curve does more nearly go through the discrepant points. In terms of the adjusted $x^{\prime}$ scale the distance from the bottom to the top of category 1 is about twothirds of that across category 2. This is important when estimating radiological progression. The linear relationship (equation (1)) has to be recalculated with all average category values scored in the adjusted scale. Hence it is now a least squares fit of the difference between $x^{\prime}$ values and their expected ones which we shall identify by $\mathrm{X}^{\prime}$. The new estimates with their standard errors are:-

$$
\begin{aligned}
& b_{\mathrm{O}}=2.533 ; \quad \mathrm{b}_{\mathrm{C}}=0.180 \pm 0.031 ; \\
& \mathrm{b}_{\mathrm{Q}}=7.29 \pm 4.85 ; \mathrm{b}_{\mathrm{S}}=0.776 \pm 0.843 .
\end{aligned}
$$

The ratios of these values are not so different from the previous ones as to necessitate re-ranking for the third time.

The very large value of $b_{Q}$, the coefficient for quartz, compared with the others raises some interesting problems. The standard errors of $b_{Q}$ and $b_{s}$ are very large, but this is mainly because the quartz and silicate contents are highly correlated in the 29 cases for which these coefficients are calculated. (Case 38 was removed at this stage since further pathological study revealed pulmonary haemosiderosis which itself produces radiological changes.) The correlation coefficients are:-

$$
\begin{aligned}
& r_{Q, S}=0.797 ; r_{C, Q}=0.204 ; r_{C, S}=0.186 \\
& r_{x^{\prime}, C}=0.763 ; r_{x^{\prime}, Q}=0.541 ; r_{x^{\prime}, S}=0.507
\end{aligned}
$$

The result is that an error in one direction in $b_{S}$ tends to be compensated by an opposite one in $b_{Q}$, so that again the estimate of the combined contribution $b_{Q} Q+b_{S} S$ is much more reliable than the separate ones. For estimating expected radiological change it matters little whether or not we separate quartz from silicates. But the underlying mechanism of a contribution per gram of quartz that is 40 times that of carbon must be very different from one in which the contribution from both quartz and silicates is, say, only 10 times that of carbon. If the very high contribution from quartz is real, it must be due to a tissue reaction that, although small, changes the radiological picture. If the reaction is not progressive it should still be related to the reticulin and collagen gradings, whilst if it is progressive the period of retention of the dust also comes in, as will be seen.

\subsection{Contribution to Radiological Changes Due to Carbon and Mineral Content}

If the contributions to radiological change per gram from quartz and silicates are really about the same, yet considerably larger than that for carbon, this could be due to unequal absorption of $x$ rays. For the same beam of $x$ rays, the absorptions by equal weights of quartz, mica, and kaolin are not very different but all are much larger than that for carbon. This is considered in detail in section 5.0.

When quartz and silicates are counted together the best (least squares) estimate relating dust contents to $x$-ray changes, measured, of course, in the adjusted scale, is

$$
\begin{array}{ll}
\mathbf{X}^{\prime} & =\mathbf{B O}+\mathbf{B C C}_{\mathbf{C}}+\mathbf{B M}_{\mathbf{M}} \\
\text { where } & \mathbf{M}=\mathbf{Q}+\mathbf{S} \\
\text { and } & \mathbf{B O}=2.31 \pm 0.734 \\
& \mathbf{B C}=0.19 \pm 0.028 \\
\mathbf{B M}_{\mathbf{M}}=1.76 \pm 0.43
\end{array}
$$

The ratio of mineral to carbon contributions per gram to radiological changes is now 9.3 to 1 ; the lower $5 \%$ confidence limit for this estimate is 5.0 and the upper one 15.3 (details in Appendix C). The mean mineral content for the 29 cases is $1.563 \mathrm{~g}$., that for carbon $12.51 \mathrm{~g}$.; for a lung with these average amounts and a $9 \cdot 3$ to 1 ratio, slightly more than half of the radiological change is due to the mineral component. Over the whole series of

TABLE 6

VALUES OF ADJUSTED SCALE $x^{\prime}$ CORRESPONDING TO QUARTER CATEGORIES OF RADIOLOGICAL CONTINUUM SCALE $x$

\begin{tabular}{cccccccccc}
\hline$x$ & 0.75 & 1.0 & 1.25 & 1.5 & 1.75 & 2.0 & 2.25 & 2.5 & 2.75 \\
\hline$x^{\prime}$ & 4.5 & 5.2 & 5.6 & 6.0 & 6.6 & 7.3 & 8.2 & 3.0 \\
\hline
\end{tabular}


cases, however, the carbon content accounts for more of the variation in radiological change.

\subsection{Second Comparison of Observed and Expected Radiological Readings}

Observed and expected (average) categories, allowing for carbon and mineral dusts separately, but not separating quartz from silicates, are shown in Fig. 10 in the adjusted radiological scale. The observed ones, $\mathrm{x}^{\prime}$, are plotted against values of $0 \cdot 19 \mathrm{C}+1 \cdot 76 \mathrm{M}$ so that expected ones, $\mathrm{X}^{\prime}$, lie on the $45^{\circ}$ line, and distances above and below it correspond to overand under-reading and to factors influencing this that are still not accounted for. (The 11 cases where all readings were zero have also been plotted at the $\mathbf{x}^{\prime}$ values corresponding to their average $\mathbf{X}^{\prime}$ value of 3.68.) These distances, conveniently expressed to the nearest whole number as $10\left(x^{\prime}-X^{\prime}\right)$, are given in Table 7. They show no systematic trend, and from the graph too the relationship seems reasonably linear. There appears to be no systematic relation to age, years undergound, or emphysema. Most of the larger deviations are seen to occur in nine cases with fibrous dust nodules. Several occurred in cases with both nodules and focal emphysema. General emphysema did not appear to have influenced the readers. The nine cases account for about $65 \%$ of the sum of the squares of the residual deviations $(P<0.01)$ : this large sum is mainly due to five out of the nine cases. When these nine cases were removed from the analysis, the values of the coefficients ' $B$ ' were only slightly different. The standard errors were smaller but it seemed better not to reanalyse the data on the basis of a few exceptional cases. The largest unexplained discrepancy is in Case 43. This case could not be included in the regression analysis since all the radiological readings were category 3 .

The iron content of 13 cases was later estimated to see if this was relevant. Case 38, with haemosiderosis, contained over four times the average amount of iron in the other 12 cases. But there was no evidence in this latter group of any relation between iron content and the radiological reading.

The results as yet are therefore compatible with the physical explanation of the radiological changes. If the mineral dust also has a biological effect this probably depends on the time it has been retained in the lung. The periods of dust retention are certainly relevant to the amount of reticulin and collagen found in the dust foci.

\subsection{Periods of Dust Retention and an Estimate of Amount of Progressive Tissue Reaction}

Tissue reaction to dust probably begins as soon as the dust is deposited and continues over a long

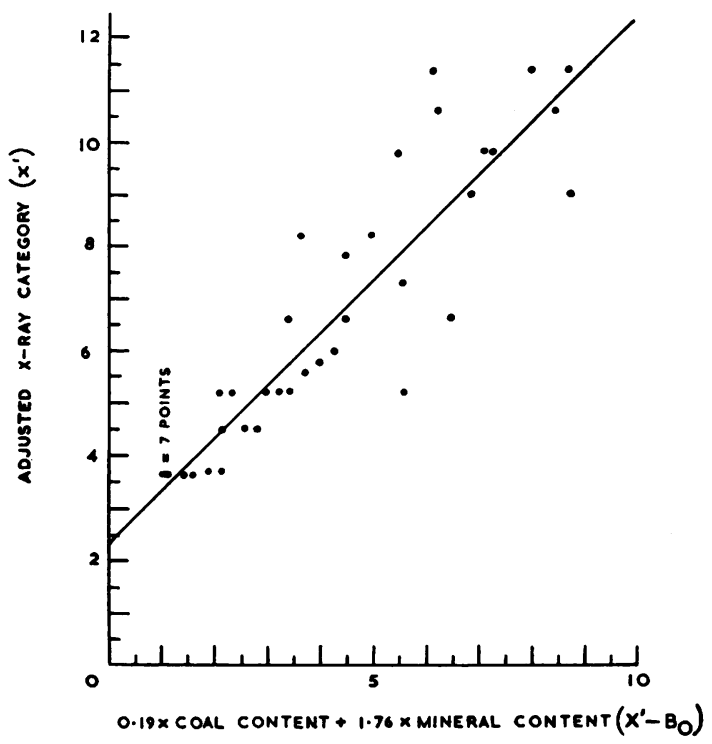

FIG. 10.-Observed values on the adjusted radiological scale $\left(x^{\prime}\right)$ compared with the predicted values $\left(X^{\prime}-B_{0}\right)$ obtained from equation 2 .

period. The amount of reaction, or possibly the chance of any occurring at all, gradually increases with time. If it depends both on amount of dust deposited and on time, and the lungs of two subjects contain the same amount of dust, more reaction should be found in the lung of the subject with the longer period of exposure. And if both periods of exposure and the amounts of dust are equal, there should be less pathological change at the end of exposure than say 10 years afterwards.

The periods of dust exposure were known (from the data on periods of years worked underground) but nothing was known of the amounts of dust to which the cases had been exposed. Furthermore it was not known how the rates of retention of dust of the individual miners varied within these periods. We have therefore assumed that the rate was constant for an individual.

The model assumed then is that each unit of dust, when it arrives at its focus of deposition, has a fixed probability of starting a reaction by which new tissue is formed at a constant rate; this rate is proportional to the amount of dust in the focus. The total amount of tissue formed during the life of an individual is then proportional to the amount of dust retained and to the average period of dust retention. We shall call this average the "mean age of dust foci". It is best to measure time backwards from the year the man died. If there was only one period underground, between $T_{1}$ to $T_{2}$ 
TABLE 7

ESTIMATED OVER- OR UNDER-READING OF RADIOGRAPHS IN RELATION TO EMPHYSEMA AND FIBROUS DUST NODULES

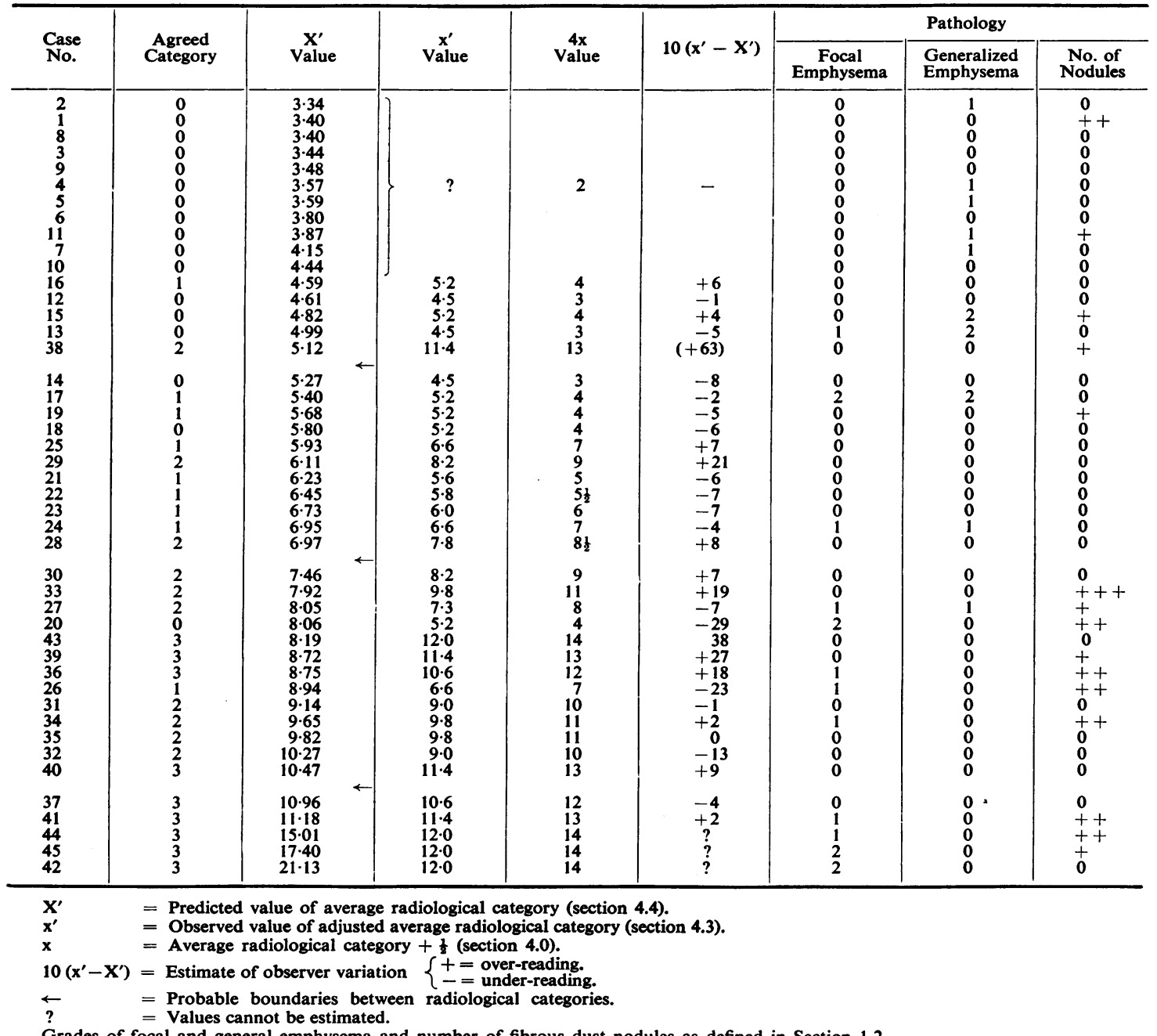

years before death, the "mean age", assuming uniform retention, is $\frac{1}{2}\left(T_{1}+T_{2}\right)=T$. If a miner spent several periods underground (as with most of our cases) the estimate is more complex. We can consider, for example, a man who worked underground between $T_{1}$ and $T_{2}$ years ago, between $T_{3}$ and $T_{4}$ years ago, and between $T_{5}$ and $T_{6}$ years ago, whilst in between these times he was not underground and, we assume, not inhaling coal and siliceous mineral dust, as depicted in Fig. 11. We assume that the "mean age of dust foci" produced between $T_{6}$ and $T_{5}$ is $\frac{1}{2}\left(T_{6}+T_{5}\right)$ and that the amount of dust foci is proportional to the length of this period, $T_{6}-T_{5}$. Similarly we have an amount $T_{4}-T_{3}$ of "mean age" $\frac{1}{2}\left(T_{4}+T_{3}\right)$. Thus the overall "mean age of the foci" is :$\frac{1}{2}\left(T_{6}+T_{5}\right)\left(T_{6}-T_{5}\right)+\frac{1}{2}\left(T_{4}+T_{3}\right)\left(T_{4}-T_{3}\right)+\frac{1}{2}\left(T_{2}+T_{1}\right)\left(T_{2}-T_{1}\right)$ $\left(T_{6}-T_{5}\right)+\left(T_{4}-T_{3}\right)+\left(T_{2}-T_{1}\right)$

or $\quad\left(T_{6}{ }^{2}-T_{5}{ }^{2}+T_{4}{ }^{2}-T_{3}{ }^{2}+T_{2}{ }^{2}-T_{1}{ }^{2} 2 T_{G}\right)$

where $T_{G}$ is the number of years underground.

The dust once deposited in a focus is assumed to remain there although a small proportion may be removed to the lymph glands in the first few months after deposition. Some may also be eliminated via the bronchial tree especially when inflammation occurs. The lymph nodes analysed in some of the 
cases contained only a small fraction of the dust in the whole lung.

The rate of retention of dust might, however, be far from uniform. How much difference this might make is worth investigating in a simple case.

Suppose there is one period underground, between $T_{1}$ and $T_{2}$ years ago, and that the same amount of dust is retained either (i) only between $T_{1}$ and $\frac{1}{2}\left(T_{1}+T_{2}\right)$ years ago, or (ii) only between $\frac{1}{2}\left(T_{1}+T_{2}\right)$ years and $\mathrm{T}_{2}$ years ago. Obviously the "mean ages" of the dust foci are decreased in the first case to $\frac{3}{4} \mathrm{~T}_{1}+1 \mathrm{~T}_{2}$ and increased in the second case to $1 T_{1}+\frac{3}{4} T_{2}$ years. The greatest relative change is for $T_{1}=0$, when in the first case the "mean age" is halved. This seems a larger error than one would expect to get, yet the variation of TM values, i.e., product of mean age of dust foci and total mineral dust (Table 8), for the 45 cases is very much larger than this error. A more realistic error of $50 \%$ in the values corresponds to five to 10 places in the ranking of $\mathrm{T}$ values, except for extreme values, where it is much less. It is worth while studying these estimates based on uniform retention of dust even if they are subject to a large error.

\subsection{Age of Dust Foci and Radiological Changes}

Table 8 (column 5 ) gives the estimates of mean age of dust foci, T, for all subjects; they vary from 8.5 to $34 \cdot 0$. As high $T$ values were associated with a low dust content in some cases and with a high dust content in others, it was expected that the effects of periods of dust exposure and the amounts of dust retained in the lung would be distinguishable.

TABLE 8

THE VARIOUS FACTORS INVOLVING TIME

\begin{tabular}{|c|c|c|c|c|c|c|c|c|c|}
\hline Case No. & $\begin{array}{c}\text { TM } \\
\text { (g. yr.) }\end{array}$ & $4 x$ & $\underset{\text { Rank }}{T}\left(\begin{array}{c}(C+M) \\
\text { (C) }\end{array}\right.$ & $\underset{\text { Years }}{T}$ & $\underset{\text { Years }}{\mathbf{T}_{\mathrm{G}}}$ & $\begin{array}{c}\text { Radiological } \\
\text { Progression } \\
\text { per Year }\end{array}$ & $\begin{array}{c}\text { Reticulin } \\
\text { Grade }\end{array}$ & $\begin{array}{l}\text { Collagen } \\
\text { Grade }\end{array}$ & $\begin{array}{c}\text { No. of } \\
\text { Nodules }\end{array}$ \\
\hline $\begin{array}{c}9^{*} \\
8^{*} \\
12^{*} \\
2 \\
6 \\
19^{*} \\
3^{*} \\
4 \\
14^{*} \\
5 \\
11 \\
25 \\
1 \\
21 \\
40 \\
28^{*} \\
10^{*} \\
7 \\
30^{*} \\
16 \\
13 \\
35 \\
22^{*} \\
38 \\
43^{*} \\
15 \\
17 \\
37 \\
18 \\
41 \\
39 \\
31^{*} \\
33^{*} \\
29 \\
32 \\
24 \\
26 \\
23 \\
27 \\
20 \\
36 \\
34 \\
44 \\
45 \\
42\end{array}$ & 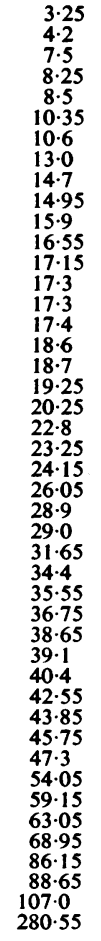 & $\begin{array}{c}2 \\
2 \\
3 \\
2 \\
2 \\
4 \\
2 \\
2 \\
3 \\
2 \\
2 \\
7 \\
2 \\
5 \\
13 \\
8 \frac{1}{2} \\
2 \\
2 \\
9 \\
4 \\
3 \\
11 \\
5 \frac{1}{2} \\
13 \\
14 \\
4 \\
4 \\
12 \\
4 \\
13 \\
13 \\
10 \\
11 \\
9 \\
10 \\
7 \\
7 \\
6 \\
8 \\
4 \\
12 \\
11 \\
14 \\
14 \\
14\end{array}$ & $\begin{array}{r}1 \\
2 \\
6 \\
3 \\
4 \\
18 \\
5 \\
10 \\
15 \\
11 \\
12 \\
30 \\
7 \\
23 \\
29 \\
14 \\
9 \\
8 \\
24 \\
19 \\
20 \\
42 \\
22 \\
13 \\
31 \\
16 \\
26 \\
41 \\
25 \\
44 \\
35 \\
28 \\
27 \\
17 \\
39 \\
33 \\
38 \\
19 \\
32 \\
37 \\
40 \\
34 \\
43 \\
45 \\
36\end{array}$ & 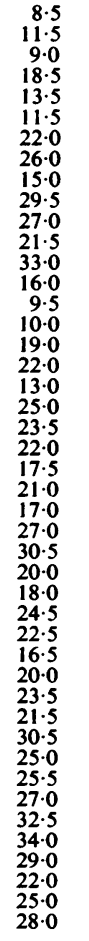 & $\begin{array}{l}17 \\
16 \\
17 \\
29 \\
14 \\
23 \\
40 \\
38 \\
30 \\
15 \\
34 \\
35 \\
14 \\
20 \\
15 \\
6 \\
38 \\
36 \\
26 \\
38 \\
39 \\
32 \\
35 \\
26 \\
34 \\
27 \\
26 \\
34 \\
36 \\
41 \\
30 \\
28 \\
40 \\
45 \\
27 \\
25 \\
29 \\
35 \\
34 \\
25 \\
16 \\
38 \\
44 \\
28 \\
46\end{array}$ & 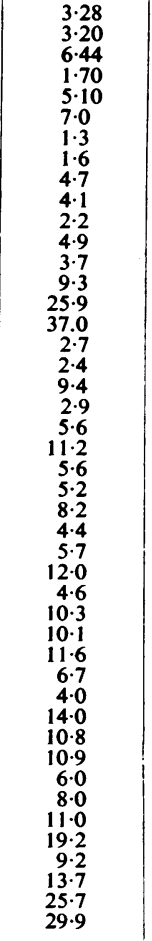 & $\begin{array}{l}1 \\
0 \\
1 \\
2 \\
0 \\
1 \\
1 \\
2 \\
1 \\
0 \\
0 \\
1 \\
1 \\
32 \\
2 \\
1 \\
2 \\
1 \\
1 \\
0 \\
2 \\
1 \\
1 \\
1 \\
1 \\
1 \\
1 \\
3 \\
1 \\
1 \\
3 \\
2 \\
2 \\
0 \\
2 \\
1 \\
3 \\
1 \\
1 \\
1 \\
2 \\
1 \\
2 \\
3 \\
3 \\
3\end{array}$ & $\begin{array}{l}+ \\
0 \\
++ \\
+ \\
+ \\
+++ \\
+ \\
+ \\
0 \\
+ \\
++ \\
+ \\
+++ \\
++ \\
++ \\
+ \\
++ \\
+ \\
+++ \\
++ \\
++ \\
++ \\
+++ \\
++ \\
+++ \\
++ \\
+++ \\
++ \\
+++ \\
+++ \\
++ \\
0 \\
++ \\
++++ \\
++ \\
+++ \\
+++ \\
++ \\
+++ \\
+++ \\
+++ \\
+++ \\
++\end{array}$ & $\begin{array}{l}\text { } \\
+ \\
+ \\
+ \\
+ \\
+ \\
+ \\
+ \\
+ \\
+ \\
+ \\
+ \\
+ \\
+ \\
+ \\
+ \\
+ \\
+ \\
+\end{array}$ \\
\hline
\end{tabular}


$\Delta$ PERIODS OF DUST EXPOSURE

PERIODS FREE FROM DUST EXPOSURE

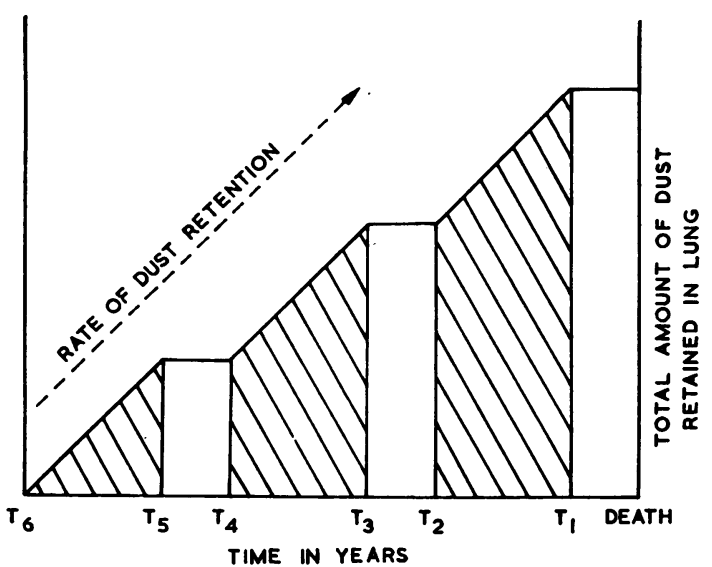

Fig. 11.-Amount of dust in the lungs, assumed to be retained at a constant rate, plotted against time for a miner who was exposed to dust for three separate periods. The estimated amount of progressive tissue reaction is the sum of the shaded and unshaded areas. (Diagrammatic representation.)

In Table 8 the cases are ranked in order of the product of mean age of dust foci and amount of mineral dust, i.e., TM values. These values are estimates of progressive tissue reaction if caused by mineral dust only. (Similarly TQ is an estimate of such tissue reaction if caused by quartz alone. These are not given in the table since they are nearly proportional to the TM values.) The corresponding ranking of product of total dust and mean age of dust foci $T(C+M)$ is tabulated. It is clear from Table 8 that the product for both mineral dust alone and total dust are only slightly correlated with average radiological category.

The radiological changes may still be explained in terms of a "mixed" hypothesis, with one contribution to the changes dependent on the weight of coal (carbon) dust independent of time, and another due to the product of the quartz component and its average period of retention in the lung. However, both the total and partial correlations of this product with the average radiological category, on the adjusted $\mathrm{x}^{\prime}$ scale, are considerably less than those for quartz and minerals alone. The partial coefficients allow for the fact that the carbon content is correlated both with $x^{\prime}$ and the quartz and silicate mineral content. The coefficients for quartz, $Q$, and its product with mean age of dust foci, TQ, compared with the original ones for quartz and total minerals are as below:-

TOTAL AND PARTIAL CORRELATION COEFFICIENTS WITH $\mathbf{x}^{\prime}$

\begin{tabular}{c|c|c|c|c|c}
\hline & \multicolumn{2}{|c|}{ Total } & \multicolumn{3}{|c}{ Partial } \\
\cline { 2 - 6 }$r_{\mathbf{x}^{\prime}, \mathrm{M}}$ & $\mathrm{r}_{\mathbf{x}^{\prime}, \mathrm{Q}}$ & $\mathrm{r}_{\mathbf{x}^{\prime}, \mathrm{TQ}}$ & $\mathrm{r}_{\mathbf{x}^{\prime}, \mathrm{M} / \mathrm{C}}$ & ${ }^{\prime} \mathbf{x}^{\prime}, \mathrm{Q} / \mathrm{C}$ & $\mathrm{r}_{\mathbf{x}^{\prime}, \mathrm{TQ} / \mathrm{C}}$ \\
\hline 0.548 & 0.541 & 0.369 & 0.632 & 0.609 & 0.455 \\
\hline
\end{tabular}

Inclusion of category 0 cases would increase the difference between these correlations, for three of the 11 cases plotted at $x=\frac{1}{2}$ have high values of TQ and of TM. This evidence strongly suggests that radiological changes for a given amount and composition of dust depend little, if at all, upon the time the dust has been retained in the lungs.

\subsection{Reticulin, Collagen, and Fibrous Dust Nodules}

Since the characteristic reaction of the lung to dust appears to be the formation of reticulin around aggregates of dust-laden phagocytes, we expected that the grades of reticulinosis would tend to increase both with the amount of dust in the lung and with the time the dust had been retained. Whilst such a slight trend does exist, the correlation is not good and is, in fact, little better than the relation to age, total dust or mineral content, or with average radiological category.

Only among the grade 3 reticulins are the mean ages of dust foci (T) high, ranging from 22:0-32-5. In the other grades there is considerable scatter; 8.5-29.5 for grade $0,9 \cdot 0-34 \cdot 0$ for grade 1 , and $10 \cdot 0-32.5$ for grade 2 . It would appear, therefore, that the degree of reticulin reaction depends more upon individual response than upon any of the factors outlined above.

A study of the distribution of collagen grade in relation to reticulin grade (Table 5) is interesting. It is generally believed that collagen is formed by maturation of reticulin (Jackson, 1953). If so, we expect that maturation would occur earlier the more reticulin was present, and therefore that higher collagen grades should occur earlier in those lungs with higher reticulin grades. This does not seem to happen in our group of cases, because within each reticulin grade the degree of collagen formation is not related to the mean age of dust foci. The increase of collagen grade from + to ++ and from ++ to +++ occurs at about the same values for mean age of dust foci in all reticulin grades; in particular there is no sign of a difference between reticulin grades 1 and 2 . The reticulin 0 s and $3 \mathrm{~s}$ look different but only because nearly all the collagen grades and $\mathrm{T}$ values are low for the $0 \mathrm{~s}$ and high for the 3s. Thus if our assumptions about the 
value of $\mathrm{T}$ are correct it appears that collagen is not necessarily arising from reticulin.

The lowest collagen grades for both reticulin is and $2 \mathrm{~s}$ correspond, with one exception, to the lungs with the lowest total dust content. Hence there may be a threshold of dust content above which added dust provides a 'secondary' stimulus to increase the amount of collagen. Once this occurs the progress of collagen development appears to be independent of the amount of dust and seems to depend both on time and individual response. From Table 8 and Fig. 12 we see a definite trend of increase in collagen grade with increase in values of the product of mean age of dust foci and mineral dust content (TM). This trend is independent of the reticulin grade.

The presence of fibrous dust nodules also increases with TM values (Fig. 13). The lung with the most nodules showed almost a complete absence of macular dust foci and had a low total content, but it contained a moderate amount of mineral dust and had a fairly high $\mathrm{T}$ value.

Figs. 12 and 13 also show that there is little or no relation between radiological category and the presence of either collagen or fibrous dust nodules.
Unequal Physical Absorption as an Explanation of Radiological Changes

\subsection{Difference in Absorption Between Carbon and} Minerals

As mentioned in section 4.4 , the various components of dust do not absorb $x$ rays equally. Are the differences large enough to account for about a 9 to 1 ratio of radiological change per gram of quartz and silicates compared with carbon, or possibly, a much larger ratio for quartz alone as compared with carbon?

We compared some of the mass absorption coefficients of these dust components. The mass absorption coefficient is defined as the relative reduction in intensity, per gram of absorbing material, in a parallel beam of $x$ rays of unit cross section; the absorbing material can be in the form of a thin layer or small particles (for full definitions see Robertson, 1956). For the wavelengths used in chest radiographs only the scatter coefficients $\sigma / \rho$ and the photoelectric coefficients $\tau / \rho$ are relevant. (In the usual notation, $\sigma$ and $\tau$ are corresponding linear absorption coefficients and $\rho$ is the density. The mass absorption coefficient is $\left.\frac{\sigma+\tau}{\rho}\right)$.

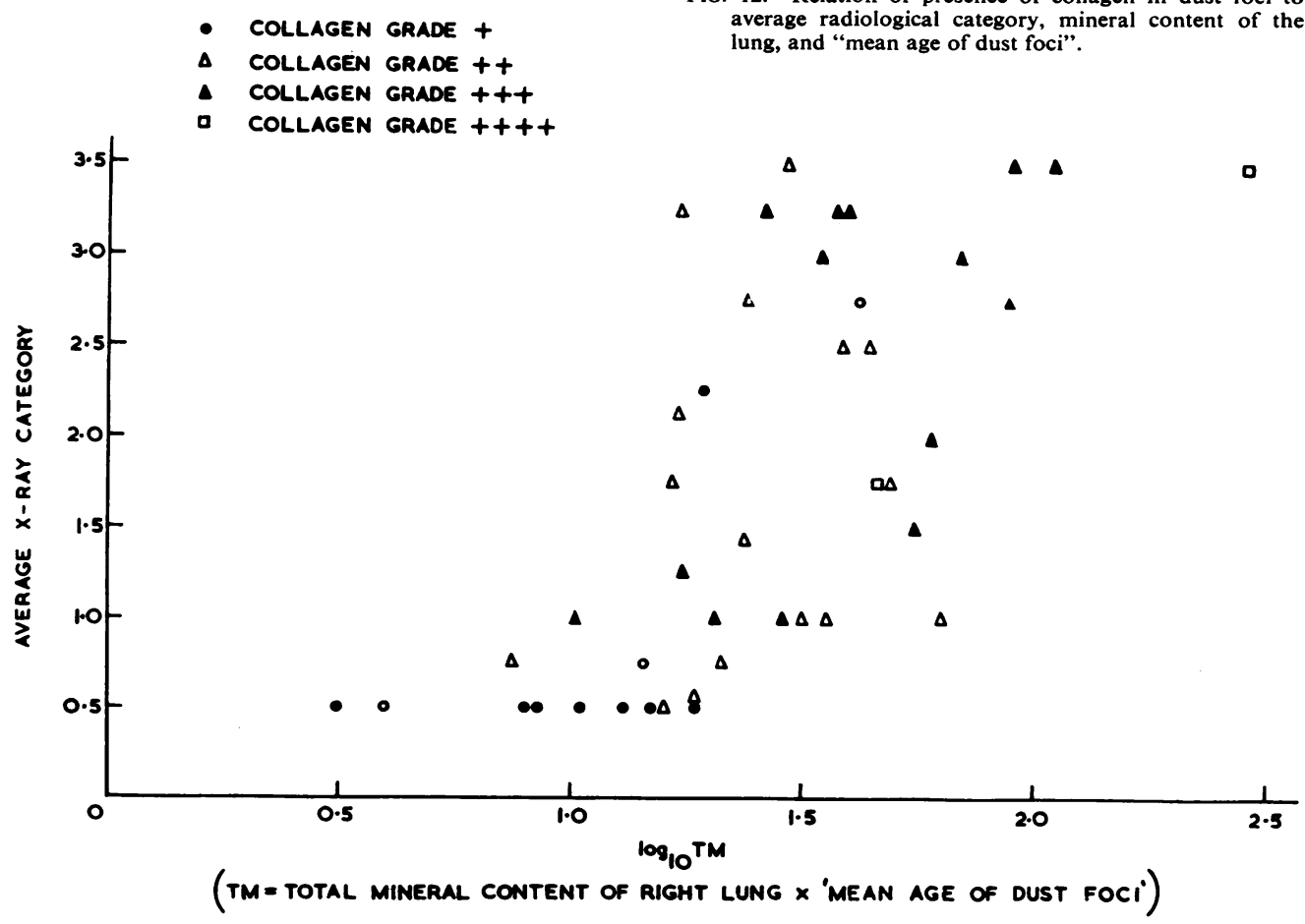

IG. 12.-Relation of presence of collagen in dust foci to average radiological category, mineral content of the lung, and "mean age of dust foci". 


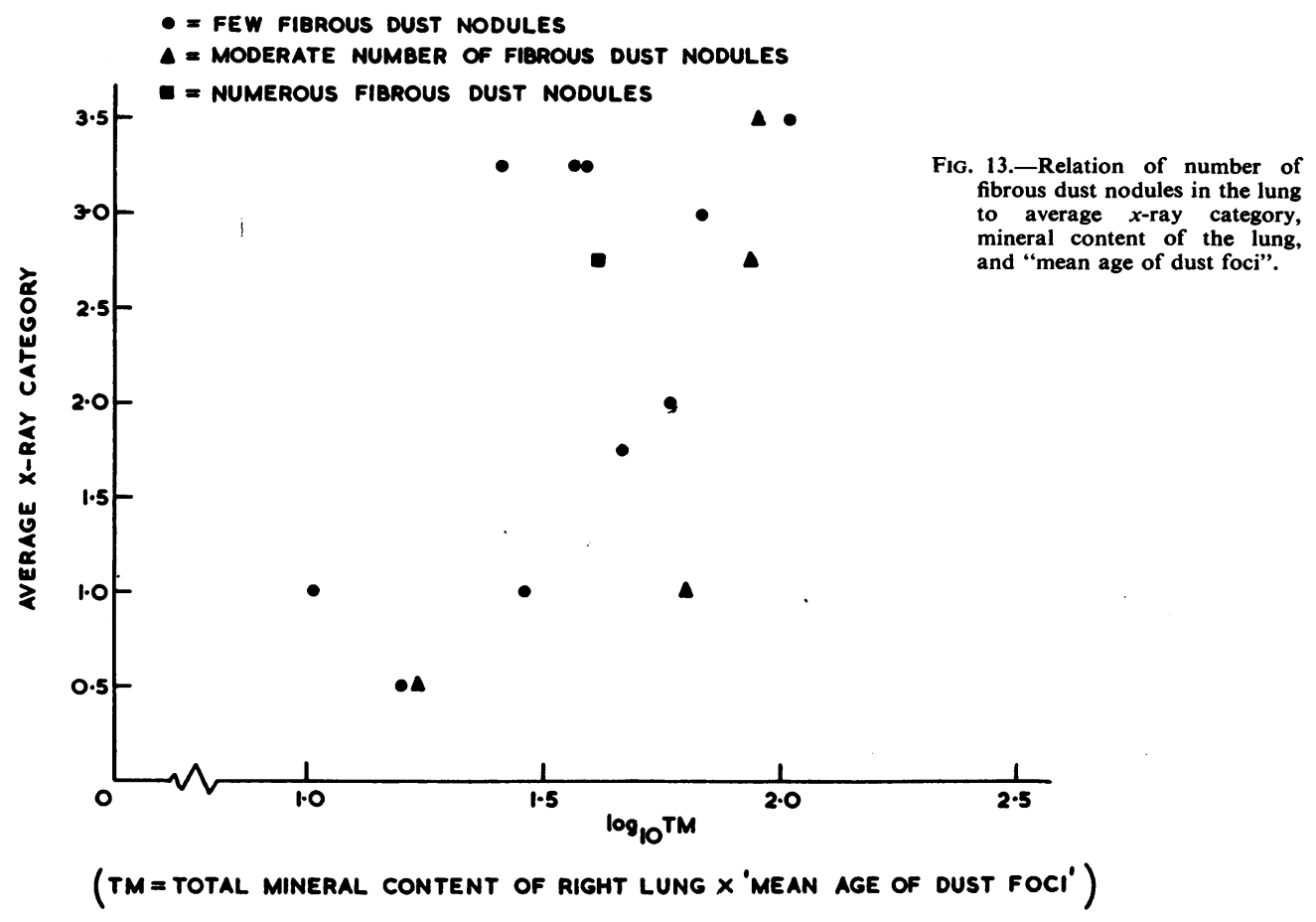

Tables 9 and 10 give the scatter and photoelectric coefficients for various wavelengths $(\lambda)$ of $x$ rays, corresponding to photon energies between 5 and 65 kilo-electron voltages (energy in $\mathrm{keV} .=12 \cdot 4 / \lambda$ ). The scatter coefficients are almost identical for $\mathrm{C}, \mathrm{O}, \mathrm{Al}, \mathrm{Si}$, and $\mathrm{K}$ over all this range, and also for

compounds of these elements. Part of the scattered radiation reaches the $x$-ray film and its main effect is to reduce the overall contrast in it.

For the longer wavelengths the photoelectric coefficients are much larger than those for scatter. At any one wavelength the photoelectric coefficients

TABle 9

ELECTRON SCATTER COEFFICIENTS, $\sigma / \rho$, FOR VARIOUS ELEMENTS

\begin{tabular}{|c|c|c|c|c|c|c|c|}
\hline & Element & Hydrogen & Carbon & Oxygen & Aluminium & Silicon & Potassium \\
\hline \multicolumn{2}{|c|}{ Atomic No. (Z) } & 1 & 6 & 8 & 13 & 14 & 19 \\
\hline \multicolumn{2}{|c|}{ Atomic Weight (A) } & $1 \cdot 008$ & $12 \cdot 01$ & $16 \cdot 00$ & 26.97 & $28 \cdot 06$ & $39 \cdot 10$ \\
\hline $\mathrm{cm} \cdot{ }^{2 / \rho} \mathrm{g} \cdot{ }^{-1}$ & $\begin{array}{r}65 \mathrm{keV} .(\lambda=0.191 \AA) \\
45 \mathrm{keV} \cdot(\lambda=0.275 \AA) \\
25 \mathrm{keV} \cdot(\lambda=0.496 \AA) \\
5 \mathrm{keV} .(\lambda=2.479 \AA)\end{array}$ & $\begin{array}{l}0 \cdot 390 \\
0.363 \\
0 \cdot 340 \\
0 \cdot 321\end{array}$ & $\begin{array}{l}0 \cdot 162 \\
0 \cdot 171 \\
0 \cdot 183 \\
0 \cdot 196\end{array}$ & $\begin{array}{l}0 \cdot 162 \\
0 \cdot 172 \\
0 \cdot 183 \\
0 \cdot 196\end{array}$ & $\begin{array}{l}0 \cdot 156 \\
0 \cdot 165 \\
0 \cdot 176 \\
0 \cdot 189\end{array}$ & $\begin{array}{l}0 \cdot 162 \\
0 \cdot 171 \\
0 \cdot 182 \\
0 \cdot 196\end{array}$ & $\begin{array}{l}0 \cdot 158 \\
0 \cdot 167 \\
0 \cdot 178 \\
0 \cdot 191\end{array}$ \\
\hline
\end{tabular}

TABLE 10

PHOTOELECTRIC MASS ABSORPTION COEFFICIENTS, $\tau / \rho$, FOR SUBSTANCES IN COALWORKERS' LUNGS*

\begin{tabular}{|c|c|c|c|c|c|c|}
\hline & Substance & $\begin{array}{c}\text { Carbon } \\
\text { (C) }\end{array}$ & Wet Tissue & $\underset{\left(\mathbf{H}_{4} \mathbf{A l}_{2} \mathbf{S i}_{\mathbf{2}} \mathbf{O}_{\mathbf{9}}\right)}{\text { Kaoolin }}$ & $\begin{array}{l}\text { Quartz } \\
\left(\mathrm{SiO}_{2}\right)\end{array}$ & $\begin{array}{c}\mathrm{Mica} \\
\left(\mathrm{KH}_{\mathbf{2}} \mathrm{Al}_{\mathbf{3}}\left(\mathrm{SiO}_{4}\right)_{3}\right)\end{array}$ \\
\hline \multicolumn{2}{|c|}{ Density $(\rho)$} & $1 \cdot 3$ & $1 \cdot 1$ & 2.6 & $2 \cdot 6$ & 2.8 \\
\hline $\mathrm{cm}^{\tau / \rho}{ }^{2 \mathrm{~g}} .^{-1}$ & $\begin{array}{r}65 \mathrm{keV} .(\lambda=0 \cdot 191 \AA) \\
45 \mathrm{keV} \cdot(\lambda=0.275 \AA) \\
25 \mathrm{keV} .(\lambda=0.496 \AA) \\
5 \mathrm{keV} .(\lambda=2.479 \AA)\end{array}$ & $\begin{array}{l}0.00744 \\
0 \cdot 0226 \\
0 \cdot 140 \\
18 \cdot 34\end{array}$ & $\begin{array}{c}0.0168 \\
0.0512 \\
0.314 \\
39.65\end{array}$ & $\begin{array}{c}0.0644 \\
0 \cdot 1860 \\
1.049 \\
106 \cdot 7\end{array}$ & $\begin{array}{c}0.0758 \\
0 \cdot 218 \\
1 \cdot 224 \\
122 \cdot 8\end{array}$ & $\begin{array}{c}0.0958 \\
0.273 \\
1.401 \\
152.3\end{array}$ \\
\hline
\end{tabular}

*Obtained from Lea's formulae (see text). 
for kaolin, quartz, and mica are not very different from each other, but all are between six and 13 times the value for carbon (Table 10). Hence for a beam of $x$ rays containing a substantial proportion of radiation with longer wavelengths than say 0.5 Ångströms the differences at least in the photoelectric coefficients are of the right order of magnitude to explain a 9 to 1 ratio of the contributions of the minerals and of carbon.

For the wavelengths used in chest radiographs, the mass absorption coefficients depend only upon those for atoms, and not on how these atoms are combined. Hence the coefficient for a molecule is the average of those for its atoms, weighted by their number and (atomic) weights, or in other words, by the percentage composition by weight.

The photoelectric coefficients were calculated from Lea's (1955) formula:-

$$
\tau / \rho=0.0089 z^{4.1} \lambda p / A
$$

Here $\mathrm{z}$ is the atomic number, $\mathrm{A}$ the atomic weight, and $\lambda$ the wavelength in Ångströms. The power $p$ is 3.05 for $\mathrm{H}, \mathrm{C}, \mathrm{N}$, and $\mathrm{O}$ and 2.85 for $\mathrm{Si}, \mathrm{K}$, and $\mathrm{Al}$. Lea also gives an expression for "wet tissue":-

$$
\tau / \rho=2 \cdot 26 \lambda^{3.05}+0 \cdot 27 \lambda^{2.85}
$$

corresponding to the following percentage composition by weight :-

$\mathrm{H} \mathrm{10,} \mathrm{C} \mathrm{12,} \mathrm{N} \mathrm{4,} \mathrm{O} \mathrm{73,} \mathrm{Na} \mathrm{0.1,} \mathrm{Mg} \mathrm{0.04,} \mathrm{P} \mathrm{0.2,}$ $\mathrm{S} \mathrm{0.2,} \mathrm{Cl} \mathrm{0.1,} \mathrm{K} \mathrm{0.35,} \mathrm{Ca} \mathrm{0.01.}$

\subsection{Influence of Electron Voltage of the $x$ rays on their Absorption}

The absolute values of the photoelectric absorption coefficients (Table 10) obviously increase very rapidly with the wavelengths of the radiations, that is when the kiloelectron voltage decreases. For all the radiographs the radiation was a mixed one and the distribution of wavelengths was known to be about the same for about half of them. These were the films taken by one $x$-ray unit. We could not find in the analysis any differences other than random ones between these films and the rest. The tube potential at which these films were taken was $65 \mathrm{kV}$. This gives the highest energy $(65 \mathrm{keV})$ of an electron in the primary beam, and hence the highest possible energy of a photon in the beam of $x$ rays. Most of these $x$ rays have electron voltages between about a third and two-thirds of this (Robertson, 1956).

Some of the "softer" radiation, i.e., of low penetrating power and longer wavelengths, is absorbed by the skin and subcutaneous tissue as well as by air molecules in front of the chest. (The amount of absorption by air molecules in the lung is negligible because the density of air is so low compared with that of tissue and coal.)

However, the softer components are very important. For the amounts of dust in these miners' lungs probably no more than $0.1 \mathrm{~g}$. is in the path of 1 sq. $\mathrm{cm}$. cross section so that only a little of the harder radiation is either absorbed or scattered by the dust and almost none is absorbed by the carbon. The optimal distribution of wavelengths for producing a satisfactory chest radiograph has, of course, been found empirically by skilful radiographic technique. Clarke (1959) has found that he can produce large changes in radiographs merely by filtering out some of the longer wavelengths. Further experiments on these lines may well provide information on the amount of highly absorbing dust present in a particular lung.

At all wavelengths much more energy is absorbed by wet tissue than by either carbon or quartz or silicate dust. The radio-opacities more likely correspond to parts of the $x$-ray beam that have passed through tissue and a number of dust foci, whereas other parts of the beam have passed through tissue only.

Iron has a mass absorption coefficient about 100 times that of carbon but the radiological readings were not in general related to the iron content of the lung. This is probably explained by most of the iron being present originally as haemoglobin and hence not localized in foci. An exception is Case 38 with haemosiderosis where the iron was present in and near the dust foci. This could account for the gross "over" reading of this case. Such focal deposition of haemosiderin has been well illustrated by the work of Magarey (1951) on experimental haemosiderosis.

\section{Applications of Results of Analysis}

\subsection{Amount of Dust in Relation to Radiological Progression}

On the basis of the analysis in this paper, radiological progression can be estimated in terms of definite weights of dust. A suitable unit to take for progression is the distance from the lower to the upper end of category 1 , i.e., $2 \cdot 1$ units on the $x^{\prime}$ scale of Fig. 9 (also Tables 6, 7, and 8). If, for example, there is about 19 times as much coal as siliceous mineral, then from equation (2) this unit is $7.82 \mathrm{~g}$.: for a mixed dust with $60 \%$ coal and $40 \%$ siliceous mineral the unit is $2.57 \mathrm{~g}$. From Table 6 the distance across category 2 corresponds to 1.57 times as much dust.

The breadth of category 0 in relation to progression is more difficult to estimate. No dust 
$(\mathrm{C}=\mathrm{Q}=\mathrm{S}=\mathrm{O})$ corresponds to $\mathrm{X}^{\prime}=2 \cdot 31$. This estimate is not reliable as it depends on an extrapolation. On the category scale it corresponds to $x$ values between 0.30 and 0.35 . This is plausible if we regard $x=0$ as the only possible category in the lung without dust; the difference corresponds to dust in the lungs of a non-miner. The change between $x=0 \cdot 3$ and $x=1$ is about equal to that between $x=2$ and $x=3$.

\subsection{Estimation of Rate of Radiological Progression}

The zero value $\left(\mathrm{B}_{\mathrm{O}}\right)$ can be used to estimate the progression per year underground throughout the working life of each miner. The breadth of category 1 in the adjusted radiological $(x)$ scale (the difference between $x^{\prime}=5 \cdot 2$ and $x^{\prime}=7 \cdot 3$ ) provides a suitable unit to measure progression in amount of simple pneumoconiosis. The expression $100\left(\mathrm{X}^{\prime}-2 \cdot 31\right) / 2 \cdot 1 \mathrm{~T}_{\mathrm{G}}$ gives the rate of progression in percentage of the breadth of category 1 . Estimates of rates of progression calculated in this way for the 45 cases are given in Tables 8 and 11 and they are seen to vary considerably, and about equally for routine necropsy cases and pit accidents. There appears to be no systematic increase of rate of progression in relation to values of mean age of dust foci $(T)$ or number of years worked underground $\left(T_{G}\right)$. Such an increase would have been expected if most of the pits in which the men had worked had become progressively less dusty over the last 30 or 40 years. The results show that if any increase in rate of progression exists it is masked by large random variations. These could be due to variable dust exposures of individuals or to different individual capacities to eliminate dust from the lungs, or to a combination of both these factors.

\subsection{Observer Variation and Agreed Radiological Readings}

A detailed analysis of observer variation will not be given here but a few points are worth making. The standard error of the mean of four observations is about 0.6 of the distance across category 1 for the 29 cases. This is larger than has been found in general for single observers reading films from any one pit (Wise, in the press). However, this 0.6 includes the rounding off error to the nearest quarter category. In fact observer variation of the readers' averaged opinion was within half a category in almost three-quarters of the cases, as can be verified by comparing the $x^{\prime}$ and $\mathrm{X}^{\prime}$ values with corresponding $\mathrm{x}$ values in Table 7, although the films of many of the cases had been found difficult to read.

It is worth considering whether inclusion of the agreed reading would have been more accurate. What this agreed reading should have been is suggested by the $\mathrm{X}^{\prime}$ column in Table 7; the arrows mark the estimated category boundaries.

Table 12 shows a comparison of the final agreed radiological category with the "true" category (according to its $\mathrm{X}^{\prime}$ value) in the 14 cases in which there was no clear majority opinion in favour of a particular category. The agreed readings seemed to be "right" in eight and "wrong" in the other six cases. Only one of the "wrong" cases was close to a category boundary, but several of the "right" ones were. The agreed readings seem to represent a random choice between two adjacent categories.

\subsection{Differences between Radiological Readings of Right and Left Lungs}

One cannot simply assume that the left and the right lungs of one man contain equal

TABLE 11

FREQUENCY DISTRIBUTION OF ESTIMATED PROGRESSION* PER YEAR UNDERGROUND

\begin{tabular}{l|c|c|c|c|c|c}
\hline Rate of Progression (\%) & $1 \cdot 0-1.9$ & $2 \cdot 0-3.9$ & $4 \cdot 0-7.9$ & $8 \cdot 0-15 \cdot 9$ & $16 \cdot 0-31.9$ & $>32$ \\
\hline $\begin{array}{l}\text { Routine necropsy cases } \\
\text { Pit accident cases }\end{array}$ & 2 & 4 & 10 & 12 & 4 & 0 \\
\hline
\end{tabular}

*Progression in \% breadth of Category 1.

TABLE 12

\begin{tabular}{|c|c|c|c|c|c|c|}
\hline \multirow{2}{*}{\multicolumn{2}{|c|}{$\begin{array}{l}\text { True Category According to } X^{\prime} \text { Value with No } \\
\text { Clear Majority Opinion (of } 3 \text { to } 1 \text { ) or more }\end{array}$}} & \multicolumn{4}{|c|}{ Number of Cases "Agreed" to be } & \multirow{2}{*}{ Total } \\
\hline & & $\mathbf{0}$ & 1 & 2 & 3 & \\
\hline & $\mathbf{0}$ & 1 & 1 & $\ldots \quad-$ & - & 2 \\
\hline & 1 & 1 & 3 & 1 & - & 5 \\
\hline & 2 & 1 & $\overline{1}$ & 3 & 1 & 6 \\
\hline & 3 & - & - & - & 1 & 1 \\
\hline
\end{tabular}


amounts of dust. In 32 of our cases the radiological readings for the right and left lungs were identical but in the remaining 13 cases, with' only one exception, the sum of the four readings for the right lung was higher than that for the left. For the 29 cases used for the main analysis the mean $\mathrm{x}^{\prime}$ value for the right lungs is 7.45 and that for the left lungs is 7.08 , i.e., 0.37 less. In terms of amount of dust this difference in mean $x^{\prime}$ values amounts to $7 \cdot 3 \%$ of the weight of the dust in the right lung $\left\{\frac{0.37 \times 100}{7.45-2.31}\right\}$. This difference of 0.37 also amounts to $18 \%$ of the quantity of dust which corresponds to the distance across category 1 , $\left\{\frac{0.37 \times 100}{2 \cdot 1}\right\}$. These estimates are, of course, rather crude but the order of magnitude is probably correct.

\section{Comment}

This work provides the first quantitative evidence on how radiological changes are related to dust in the lungs of coalworkers with simple pneumoconiosis. The "I.L.O. Conference of Experts in Pneumoconiosis" (1950) recommended that simple pneumoconiosis be defined only in terms of radiological change and not on the amount of dust found in the lungs at necropsy. A reliable interpretation of the radiological changes during life in terms of amounts of various components of dust in the lungs may become possible with new radiographic techniques.

The working assumption that the amount of radiological change depends only upon the total weight of dust in the lungs was not confirmed by our results. Our evidence suggests a high contribution from the mineral dust for which there is a reasonable but by no means certain physical explanation. A biological explanation is inconsistent with the low grade tissue reaction to the dust and the poor correlation of periods of dust retention with radiological change. In any case composition must be allowed for in sampling respirable dusts in mines. A particular value in the radiological scale $(x)$ does not correspond to a definite amount of dust in the lung unless its composition is known. Also the risk of developing progressive massive fibrosis might depend on one component of the dust more than another, as suggested by King et al. (1956).

Our findings have been applied to Pneumoconiosis. Research Unit studies of radiological progression of faceworkers in single pits (the results will be published separately), and they should also be of value in the large-scale field investigations of the
National Coal Board now in progress (Fay and Rae, 1959).

The view that collagen is formed from reticulin does not fit the relationship of such tissue reactions in miners' lungs to our estimates of "mean age of dust foci". The reactions probably occur extremely slowly so that they should provide promising material for further study of the nature of fibrogenesis.

The estimates of "mean age of dust foci" are unavoidably crude but the errors are probably small compared with the very large variations of these estimates within the 45 cases. Similarly it was fortunate that both the totals and relative amounts of coal (carbon) and mineral dusts varied so widely. Thus this small number of cases, despite the many pathological features not necessarily related to dust, provided far more information on the separate effects of coal and mineral dust than perhaps several hundred cases in a more uniform group. We expect to improve all the quantitative estimates on a larger and equally varied series.

This kind of study is only possible with a great deal of help and cooperation from others. Professor J. Gough gave us free access to the routine necropsy material at the Institute of Pathology of the Welsh National School of Medicine. Drs. T. H. Jenkins, C. E. Saunders, and T. D. Spencer of the National Coal Board Medical Service arranged for one of us (D.R.) to be informed of fatalities in pit accidents in their regions and also supplied industrial histories. Drs. R. A. C. Macnair, G. B. Murray, and R. W. Thomas provided a substantial number of chest radiographs as well as industrial histories. Mr. W. G. Clarke, Professor A. L. Cochrane, Drs. J. C. Gilson, and W. E. Miall read the radiographs. The figures were drawn by Mr. W. H. Roberts, and the photomicrographs were by Mr. T. J. H. Cooke. Secretarial help was given by Mrs. F. E. Willson. Dr. J. C. Gilson, Mrs. M. McDermott, and Mr. P. D. Oldham gave valuable advice and criticism in the preparation of this paper. To all these we are extremely grateful.

Finally, we wish to thank the relatives of miners killed in pit accidents for their understanding in granting permission for a post-mortem examination.

\section{APPENDIX A}

The Continuous Function Fitted to the Distribution of Agreed Readings of Radiological Categories

As stated in Section 4.1, Fig. 6 is based on the idea that radiological change is a continuous variable, and that for populations of faceworkers in any one pit at any one time its distribution is normal on a new scale $y$. The relation between $y$ and $x$ is:-

$$
y=1\left(x^{2}-\frac{1}{x^{2}}\right)+1
$$


$x=0$ corresponds to $y=-\infty, x=1$ to $y=1$, $x=2$ to $y=1.9375, x=3$ to $y=3.2222$. It is clear in Fig. 6 how close the fitted accumulated percentages are to the observed ones. The mean of $y=\bar{y}=1.60$, and the standard deviation $\sigma=1.9477$.

The values of $x$ in terms of $y$ can easily be obtained by rewriting (1) as

$$
2 \log _{e} x=\sinh ^{-1}(2 y-2)
$$

The calculated ordinates of Fig. 6 are values of:

$$
\phi(t) \frac{d t}{d y} \frac{d y}{d x}=\phi(t)\left(x+x^{-3}\right) / 2 \sigma
$$

where

$$
t=(y-\bar{y}) / \sigma \text { and } \phi(t)=(2 \pi)^{-\frac{1}{2}} \exp \left(-\frac{1}{2} t^{2}\right)
$$

The accumulated probabilities can of course be obtained by finding $y$, then $t$, and then $\phi(t)$ from tables of the normal probability integral.

\section{A P P ENDIX B}

\section{Note on the Method of Obtaining the Adjusted Radiological Scale $\left(x^{\prime}\right)$}

The method of obtaining the $x^{\prime}$ scale is an unusual one improvised to meet an unusual difficulty. We needed a quantitative analysis without knowing what half of our quantities were, namely those depending on breadths of categories in the (original) radiological scale. The ranking method uses all the observed results, but has the disadvantage that random fluctuations in the results produce non-random ones in the relation of $\mathrm{x}^{\prime}$ to $x$. Hence deviations, from a smooth curve, of adjacent points are correlated. For this reason there is no advantage in comparing too many of the percentiles.

The second comparison of percentiles (in Fig. 6, curve b) with ranked values of $\mathbf{X}=\mathbf{b}_{C} \mathbf{C}+\mathrm{b}_{\mathrm{Q}} \mathrm{Q}+\mathrm{b}_{\mathrm{S}} \mathrm{S}$ was done in a slightly different way. The lowest three values of $X$ were averaged, then the 4 th, 5 th and 6 th, and the 7th to 9th, and so on. These were paired with the 15 percentiles $100 / 30,300 / 30,500 / 30,-$ up to $2900 / 30$.

The 45 cases were actually ranked a third time, in terms of values of $\mathbf{B}_{\mathbf{O}}+\mathbf{B}_{\mathbf{C}} \mathbf{C}+\mathbf{B}_{\mathbf{M}} \mathbf{M}$, i.e., of $\mathbf{X}^{\prime}$, as shown in Table 7, and these rankings too were compared with percentiles. This suggested that the scale was not perfectly linear but no large or systematic deviations were found.

\section{A P P E N D I X C}

Probable (confidence) limits for ratio of contributions per gram to Radiological Change from Mineral and Carbon.

These limits were obtained from Fieller's theorem (Fieller, 1944). If the "sample" ratio $B_{M} / B_{C}$ is written as $l$ and the true ratio $\beta_{M} / \beta_{C}$ as $\lambda$, then we consider the distribution of

$$
z=\mathbf{B}_{\mathbf{M}}-\lambda \mathbf{B}_{\mathbf{C}}
$$

about its true mean $\beta_{\mathbf{M}}-\lambda \beta_{\mathbf{C}}$. The distribution of $z / \sqrt{ } \operatorname{var} z$ is that of Student's $t$, with $n-3$ degrees of freedom corresponding to the $n$ pairs of observations from which the estimates $B_{O}, B_{M}$ and $B_{C}$ are obtained. We can then write

$(l-\lambda) \mathbf{B}_{\mathbf{C}} /\left\{\operatorname{var} \mathbf{B}_{\mathbf{M}}-2 \lambda \operatorname{cov}\left(\mathbf{B}_{\mathbf{M}}, \mathbf{B}_{\mathbf{C}}\right)+\lambda^{2} \operatorname{var} \mathbf{B}_{\mathbf{C}}\right\}^{\frac{1}{2}}$.

In our particular case var $B_{C}=0.0007956$; $\operatorname{cov} \mathrm{B}_{C}, \mathrm{~B}_{\mathrm{M}}=-0.002461 ; \operatorname{var} \mathrm{B}_{\mathrm{M}}=0.18731$. The negative covariance arises from the positive correlation of $\mathbf{C}$ with $\mathrm{M}$. Fortunately this correlation is not too large. The larger it is, of course, the larger is $-2 \lambda \operatorname{cov} B_{M}, B_{C}$ which widens the probable limits of $\lambda$ given $l$. For this reason the estimate of $b_{0} / b_{s}$ cannot at present be usefully given. If $\lambda=1, t=-3 \cdot 574$, with a probability of 0.0008 of being exceeded.

\section{REFERENCES}

Blacklock, J. W. S., Kennaway, E. L., Lewis, G. M., and Urquhart, M. E. (1954). Brit. J. Cancer, 8, 40.

Clarke, W. G. (1959). Personal communication.

Faulds, J. S., King, E. J., and Nagelschmidt, G. (1959). Brit. J. industr. Med., 16, 43 .

Fay, J. W. J., and Rae, S. (1959). Ann. Occup. Hyg., 1, 149.

Fieller, E. C. (1944), Quart. J. Pharm., 17, 117.

Fletcher, C. M., and Oldham, P. D. (195i). Brit.J. industr. Med., 8,138.

Gordon, R. L., and Harris, G. W. (1956). Safety in Mines Research Report No. 138.

Gough, J. (1947). In Silicosis, Pneumokoniosis and Dust Suppression in

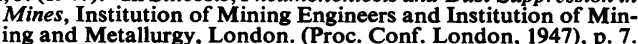
ing and Metallurgy, London. (Proc. Conf. London, 1947), p. 7. James, W. R. L.

(Lond.), 1, 28. . J. E. (1949). J. roy. micr. Soc., 69, 231.

Heppleston, A. G. (1953). J. Path. Bact., 66, 235.

International Labour Office. Third International Conference of Experts on Pneumoconiosis, Sydney, 1950. Record of Proceedings, 1, 126 (I.L.O. Geneva, 1953).

Jackson, S. Fitton (1953). In Nature and Structure of Collagen, ed. J. T. Randall, p. 141. Butterworth, London.

King, E. J. (1939). Biochem. J., 33, 944 .

King, E. and Gilchrist, M. (1945). 35ec. Rep. Ser., med. Res. Coun. and Gilchrist, M. (1945). Spec. Rep. Ser., med. Res. Coun. (Lond.), No. 250, p. 21.

Maguire, B. A., and Nagelschmidt, O. (1956). Brit. J. industr. Med., $13,9$.

and Nagelschmidt, G. (1945). Spec. Rep. Ser., med. Res. Coun. (Lond.), No. 250, p. 1 .

Lea, D. E. (1955). Actions of Radiations on Living Cells, 2nd ed. pp. 345-348. University Press, Cambridge.

Magarey, F. R. (1951). J. Path. Bact. 63, 729.

Meersseman, F. (1958). Communication No. 152. Institut d'Hygiene des Mines, Hasselt.

Robertson, J. K. (1956). Radiology Physics, 3rd ed. Macmillan, London.

Worth, G., and Schiller, E. (1954). Die Pneumokoniosen, pp. 108-154. Stauffen, Cologne. 